\title{
Evaluation of the Electrical Characteristics of Recycled Iron Reinforced Polystyrene Composites
}

\author{
S. A. Abdulkareem ${ }^{1}$, J. O. Ighalo ${ }^{1,2}$, A. G. Adeniyi ${ }^{1 *}$ \\ ${ }^{1}$ Department of Chemical Engineering, University of Ilorin, Ilorin, Nigeria \\ ${ }^{2}$ Department of Chemical Engineering, Nnamdi Azikiwe University, Awka, Nigeria
}

\section{$P A P E R I N F O$}

\section{Paperhistory:}

Received 21 April 2021

Accepted in revised form 16 May 2021

\section{Keywords:}

Electrical conductivity

Iron fillings

Plastic composite

Polystyrene

Resistivity

\section{$A B S T R A C T$}

The prospective reuse of iron fillings from the milling machine and polystyrene in the solid waste streams in the production of plastic composites were considered in this study. The preparation, electrical properties, density, void fraction and particle distributions of the solvated polystyrene filled composites were all investigated as a function of recycled iron fillings concentration. The composites were developed by hand layup technique and cured by casting under ambient conditions $\left(25 \pm 2^{\circ} \mathrm{C}\right)$ for 7 days. The compared micrographs confirmed welldispersed recycled iron fillings in polystyrene matrix and decreasing void fraction as iron filling increases in the composites. The highest electrical conductivity and density values of the composites were obtained at the highest iron filling composition of $40 \mathrm{wt} \%$ as $5.91 \times 10^{-07} \mathrm{~S} / \mathrm{cm}$ and $1.31 \mathrm{~g} / \mathrm{cm}^{3}$, respectively. The developed iron polystyrene composite has good electrical properties, making it suitable to be an alternative material for metals.

\section{INTRODUCTION}

Plastic composites filled with metal are of immense industrial impact in many areas of engineering applications [1]. Their significance hinges on the fact that their processing methods and eventual mechanical properties are generally plastics related while their emerging electrical properties are metallic $[1,2]$. The achievement of this property mix in such composites depends on many factors like type, concentration, aspect ratio, and conductivity of the additive, as well as plastic materials selected [3, 4]. The influence of the type of plastic matrix and filler on the electrical characteristics of the composite has been studied in many works $[5,6]$. Although in some reports, it was observed that the percolation behaviour of the developed conductive composite depends on both filler particle shape and spatial distribution within the plastic matrix, it is generally accepted that the filling of plastic with metallic particles results in an increase of electrical conductivity of the composites obtained [5].
Acquiring metallic material for the production of conductive composite material often involves a huge investment in the material and a direct increase in the cost of production [7]. One way of reducing the production cost but still maintaining the properties of the composite is by using a waste metallic material such as iron filings from the waste stream [8]. Iron fillings had been chosen due to their availability, low cost and high specific strength $[9,10]$. The iron fillings and polystyrene resins used in this study were obtained directly from solid waste streams. This bears significant implications for solid waste management efforts. As effort is being explored to convert waste to wealth [11-13], more intricate technologies for doing so are invariably important. Development of composites in one such important way of using these waste materials $[14,15]$.

Several researchers have been carried out investigations on the development of composites from the mixture of polystyrene and various fillers like starch, aluminium, copper and clay using injection moulding technique, hot press method and many more [16, 17].

*Corresponding Author Email: adeniyi.ag@unilorin.edu.ng (A. G. Adeniyi)

Please cite this article as: S. A. Abdulkareem, J. O. Ighalo, A. G. Adeniyi, 2021. Evaluation of the Electrical Characteristics of Recycled Iron Reinforced Polystyrene Composites, Iranian (Iranica) Journal of Energy and Environment, 12(2), pp.125-130. Doi: 10.5829/ijee.2021.12.02.04 
Researchers have investigated the electrical properties of metal-reinforced polymer materials given the application in electrical circuits and also to determine their potential as dielectrics and semiconductors. The electrical properties of plastics composites have been investigated in cases where aluminium [8], clay [17], natural fibres $[18,19]$, silicon oxide [20] and boron nitride [21, 22] were used as fillers.

In a recent review paper on the current research area, Adeniyi and Ighalo [23] observed that the electrical properties of pure metals in polystyrene composites have not been sufficiently investigated. Most studies focused on epoxy composites. Because polystyrene is another important polymer for composites development [24-26]. It is important to evaluate the electrical properties of her pure metal composites. This, therefore, presents an important gap in knowledge that this study intends to fill. This work is based on using waste solid materials as materials of conductive composite production; iron filings powders as filler and solvent-based polystyrene resin as a matrix to form a composite of desired properties using the hand lay-up method, entirely in cold processing without recourse to thermal treatment at any stage of its processing.

In the present study, iron filing powder was used as conductive filler while solvated polystyrene resin synthesized from waste polystyrene was used as a matrix. The selected materials will aid in the study of the influence of iron filing content on the electrical conductivity of the composites. Also, this research will assist in the reduction of problem associated with waste discharged in the environment and thus, reducing the cost of waste management as well as the developed composites.

\section{MATERIALS AND METHODS}

\section{Preparation of iron filings}

The iron fillings used in this study was directly obtained from the Central Engineering Workshop, the University of Ilorin after some metallic jobs of steel of known properties (Table 1) were ground. This was done to avoid

Table 1. Chemical composition of iron filings [27]

\begin{tabular}{lc}
\hline Elements & Composition $(\mathbf{w t} \%)$ \\
\hline Carbon & 3.53 \\
Silicon & 2.67 \\
Magnesium & 0.05 \\
Sulphur & 0.01 \\
Phosphorus & 0.03 \\
Manganese & 0.31 \\
Iron & 93.4 \\
\hline
\end{tabular}

the use of rusted iron fillings which could affect the results of the research. The iron filings were dried in an oven for $24 \mathrm{~h}$ at $50^{\circ} \mathrm{C}$ to remove the free water present in it [8]. The dried sample was graded to obtain the powder particle size of $150 \mu \mathrm{m}$ [1].

\section{Preparation of polystyrene resin}

The waste polystyrene was sorted from the solid waste stream of the University of Ilorin, cleaned and subjected to solvolysis to obtain a solvent-based resin of $855 \mathrm{~kg} / \mathrm{m}^{3}$ density at room temperature. The preparation methodology of the petroleum solvent based polystyrene resin has been previously described in detail [28]. The use of a petroleum solvent does not bear negative consequence on the environment because it is entirely used up during the dissolution process of waste polystyrene. Though the eventual composite developed is non-biodegradable, this is mainly because of the metal fillers used and not the resin itself. Biodegradability has been reported when biomass fillers were used for polymer composites [29]. Based on these considerations, the current approach can be considered to not have a deleterious effect on the environment.

\section{Composite development}

The composites were developed by hand layup technique. The required mass of the solvent-based polystyrene res in and prepared iron filling particles were dispensed into the mixer and mixed rigorously in one step mixing process for 5 minutes before discharging onto the roller plate for further pressing and shape forming unto a uniform cross section. Composites with $0,10,20,30$ and $40 \mathrm{wt} \%$ metallic fillers were prepared. Filler concentration did not exceed $40 \mathrm{wt} \%$ because of the aspect ratio. Because a solid powder is going into a polymeric resin, there is usually a maximu $\mathrm{m}$ amount of the solid the resin can hold to form a composite material of consistent physical integrity (this is 40\%). Above this value, the two components will not stick together to form a heterogeneous solid. Oil was smeared on the metal surface to prevent the composite from sticking and to achieve easy composites removal. The fabricated composite was spread and made to cure by casting under ambient conditions $\left(25 \pm 2^{\circ} \mathrm{C}\right)$ for 7 days [30].

\section{Measurement of resistivity}

Electrical resistances of conductive composites were measured by employing the standard four-point probe method under laboratory conditions [1]. The narrow sides of the composite film were covered with aluminium foils to facilitate measurement with the four-point probe. This technique measures resistivity by applying a constant current (in the range of 0 to $10 \mathrm{~A}$ ) and measuring the voltage drop over the center $3 \mathrm{~mm}$ thick sample. A Keithley 224 Programmable Current Source and Keithley 182 Digital Sensitive Voltmeter were used. The composite resistivity (R) was calculated by using the 
relation in Equation (1) [6].

$$
R=\frac{\rho l}{A}
$$

where $\mathrm{R}$ is the measured resistance, $\mathrm{L}$ is the length of the specimen, which is also the length of the glass slide, $w$ is the width of the specimen, which corresponds to the gap between the two adhesive strips, and $h$ is the thickness of the conductive paste. Three specimens were tested for each experimental condition. An average bulk resistivity for each sample was calculated for each sample.

\section{Measurement of density}

The experimental densities of the iron filling, solvated polystyrene and composites were obtained using the laboratory-made density setup [1]. The rule of the mixt ure was used to calculate the theoretical densities of the solvated polystyrene/iron filing composites by using the densities of the solvated polystyrene and iron fillings as $0.855 \mathrm{~g} / \mathrm{cm}^{3}$ and $7.87 \mathrm{~g} / \mathrm{cm}^{3}$, respectively. Theoretical densities of the composites were evaluated by using Equation (2) [6].

$$
\rho_{t d}=\frac{1}{\left(\frac{w_{f}}{\rho_{f}}+\frac{w_{m}}{\rho_{m}}\right)}
$$

where, $w_{f}$ and $w_{m}$ are weight fraction of the filler and matrix, respectively while $\rho_{f}$ and $\rho_{m}$ are densities of the filler and matrix, respectively. The void content in the composites was estimated by using the theoretical and experimental densities as presented in Equation (3) [6].

$$
v_{\text {void }}=\left(\frac{\rho_{t d}-\rho_{e d}}{\rho_{t d}}\right) \times 100
$$

where, $\rho_{t d}$ - theoretical density of the composite material, $\rho_{e d}$ - Experimental density of the composite materials. Morphological analysis was done with a Metallurgical microscope (Olympus BX-60 M) at a magnification of $\times 100$.

\section{RESULTS AND DISCUSSION}

\section{Electrical resistivity and conductivity of the composites}

The resistivity of Iron filings/polystyrene composites containing various mass fractions of recycled iron filing powder with the size of $150 \mu \mathrm{m}$ is presented in Figure 1 . It was seen that even at a lower concentration of filler the resistivity of composite is lower than that of cured virgin solvated polystyrene without iron filing powder, which is $1.3 \times 10^{8} \mathrm{ohm}-\mathrm{cm}$ and decreased progressively at a higher percentage of iron filler as shown in Figure 1. A similar observation of the filler loading effect has been made for copper [31] and aluminium [8] reinforced polystyrene composites. The iron filler has lesser resistivity when compared to the polymer resin [23]. Hence, increasing its proportion in the composites will invariably lead to lesser resistivity.

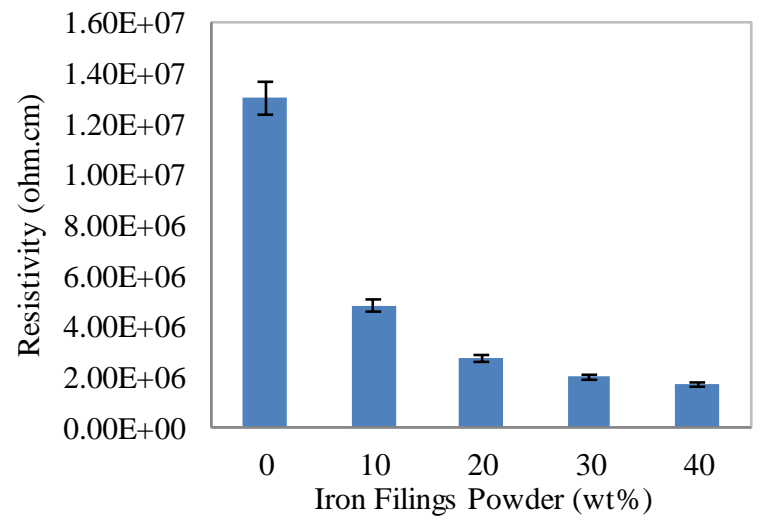

Figure 1. Effect of iron filling powders on resistivity

The electrical conductivities of the iron filling composites are shown in Table 2. As a comparison, iron filling content in polystyrene at $10 \mathrm{wt} \%$ results in $2.08 \times$ $10^{-7} \mathrm{~S} / \mathrm{cm}$. The conductivity reaches $5.91 \times 10^{-07} \mathrm{~S} / \mathrm{cm}$ for $40 \mathrm{wt} \%$ iron content in this study. The results showed a considerable increase in the electrical conductivity as the iron filling content increases, which is a confirmation of the impact of the addition of the iron fillings to the solvated polystyrene matrix. This is an enhanced conductivity achieved as compared to other studies of thermosetting matrix [32]. Also, As the amount of iron filling in the polystyrene increases more conductive paths in the composite are created. Low concentrations and poor dispersion may lower the conductivity at low wt\% of metallic content as reported by Osman and Mariatti [5]. However, local enhancement of electrical conductivity is achieved in this study as a result of the good adhesive property of solvated polystyrene that allowed better dispersion of the iron filling and the good formation of an interconnected network of iron filings in the polystyrene matrix [1]

\section{Density of the composites}

The effect of different iron filing loading in the solvated polystyrene matrix on density was investigated. Table 3 shows that polystyrene composites with $40 \%$ Iron filing content have the highest density followed by 30,20 and $10 \mathrm{wt} \%$ iron filling content, respectively. The same trend is observed with the theoretical density prediction. Since

Table 2. Effects of iron filling content on conductivity of the composites

\begin{tabular}{lc}
\hline Filler content $(\mathbf{w t} \%)$ & Conductivity $(\mathbf{S} / \mathrm{cm})$ \\
\hline 0 & $7.69 \times 10^{-08}$ \\
10 & $2.08 \times 10^{-07}$ \\
20 & $3.67 \times 10^{-07}$ \\
30 & $5.05 \times 10^{-07}$ \\
40 & $5.91 \times 10^{-07}$ \\
\hline
\end{tabular}


the iron filing has a higher density $\left(7.87 \mathrm{~g} / \mathrm{cm}^{3}\right)$ than solvated polystyrene $\left(0.855 \mathrm{~g} / \mathrm{cm}^{3}\right)$, therefore, the density of composites tends to increase as the iron filling content increases. However, the effects of the void fraction on the experimental values of density became evident by comparing the theoretical and experimental densities of the composites.

The densities of the composites compared with the theoretical values were used to find out the pore volume since it explains the air gaps (micro-voids) in the composite developed as presented in Table 3. It was observed in Table 3 that the higher the filler content, the lower the voidage fraction become; this is between $5.3 \%$ and $1.4 \%$ in the range. The void percentage decreased by the addition of iron filing filler. A higher percentage of micro-voids formed at a lower percentage of iron filling filler got decreased as the percentage of filler increased [1]. This implies that interfacial interaction is strengthened in iron filling-solvated polystyrene composite as the distance between metal particle decreases. The effective density profile obtained in this study is lighter when compared with composites developed by using other materials [32, 33]. Similar observations have also been reported in other studies [1, 23].

\section{Morphological analysis}

Microscopic examination (micrographs) on the developed conductive composites at different iron filing percentages are shown in Figure 2. It shows optical microscope images of the composites for $10 \mathrm{wt} \%$ to 40 $\mathrm{wt} \%$ contents of iron filling particle in the solvated polystyrene matrices. These micrographs also support the concept that the composites have better conductive networks as iron filling contents increases. The smoothness of the composite surface reveals a good dispersion of the filler in the matrix and the absence of any agglomerations [34]. In all of the composites produced, effective mixing is observed. It could be surmmarized from the analysis that the distribution of the iron filling in the sample is uniform at all content percentage used, with no exception; this confirms the effectiveness of the preparation method employed

Table 3. The variation in the density of poly styrene/iron fillings composites

\begin{tabular}{lccc}
\hline $\begin{array}{l}\text { Filler content } \\
(\mathbf{w t} \%)\end{array}$ & \multicolumn{2}{c}{ Density of composite $\left(\mathrm{g} / \mathbf{c m}^{\mathbf{3}}\right)$} & Void fraction \\
\cline { 2 - 3 }$(\boldsymbol{\%})$ & Theore tical & Expe rimental & \\
\hline 0 & 0.8550 & 0.8100 & 5.2632 \\
10 & 0.9387 & 0.9120 & 2.8412 \\
20 & 1.0405 & 1.0200 & 1.9693 \\
30 & 1.1671 & 1.1500 & 1.4642 \\
40 & 1.3288 & 1.3100 & 1.4120 \\
\hline
\end{tabular}

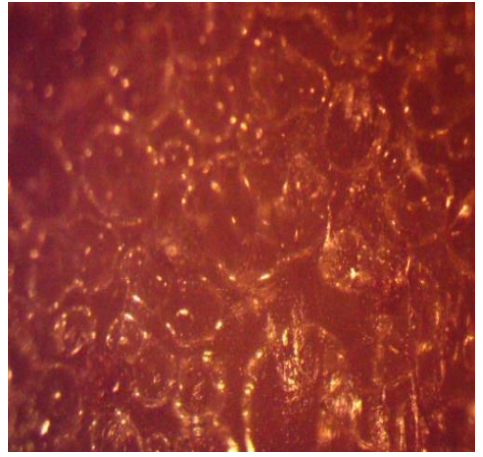

$10 \mathrm{wt} \%$

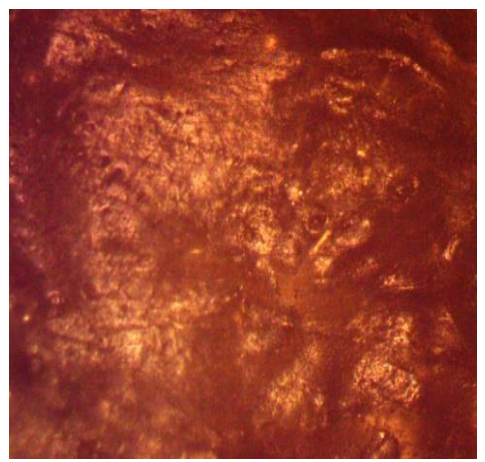

$30 \mathrm{wt} \%$

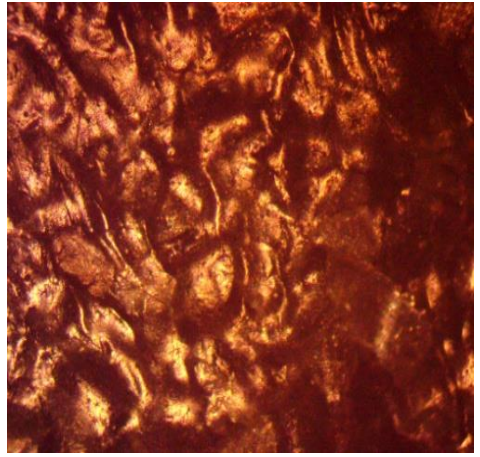

$20 \mathrm{wt} \%$

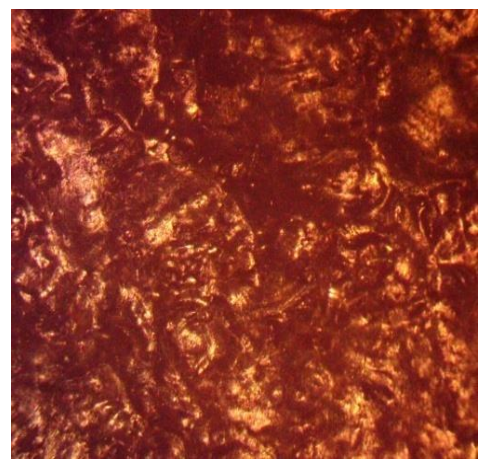

$40 \mathrm{wt} \%$

Figure 2. Micrographs of the composites at different iron filing percentages (magnification $\times 100$ ) 


\section{CONCLUSION}

The development of conductive composites has been achieved by mechanical mixing of solvated polystyrene and iron fillings. Several key conclusions were derived from the current investigation. Comparisons of micrographs in low and high magnification showed that iron-fillings in all higher fractions are well dispersed in their respective solvated polystyrene matrixes. The composites also exhibit conducting properties comparable to other similar works.

The highest electrical conductivity of the composites was obtained at the highest iron filling composition of 40 $\mathrm{wt} \%$ as $5.91 \times 10^{-07} \mathrm{~S} / \mathrm{cm}$. The highest density of the composites was obtained at the highest iron filling composition of $40 \mathrm{wt} \%$ as $1.31 \mathrm{~g} / \mathrm{cm}^{3}$.

Thus, the Iron filling-polystyrene composites prepared by simple mechanical mixing method afforded acceptable density and comparable electrical conductivity as to other related composites reported previously. The developed iron fillings-polystyrene composite has good electrical properties, making it suitable to be an alternative material for metal materials. For future work, methods of treating and modifying the fillers and/or resins can be explored to achieve improved electrical and density properties. It will be also important to try other eco-friendly solvents in the resin development process.

\section{CONFLICT OF INTEREST}

The authors declare that there are no conflicts of interest.

\section{COMPLIANCE WITH ETHICAL STANDARDS}

This article does not contain any studies involving human or animal subjects.

\section{REFERENCES}

1. Adeniyi, A.G., J.O. Ighalo and S.A. Abdulkareem, 2020. “Al, Fe and $\mathrm{Cu}$ Waste Metallic Particles in Conductive Polystyrene Composites". International Journal of Sustainable Engineering pp.1-7. http://dx.doi.org/10.1080/19397038.2020.1793426

2. Busfeld, J., A.G. Thomas and K. Yamaguchi, 2005. "Electrical and Mechanical Behaviour of Filled Elastomers". Journal of Polymer Science Part B, 43, pp.2161-2167. https://doi.org/10.1002/polb.20085

3. Mohit, H. and V. Arul Mozhi Selvan, 2018. "A Comprehensive Review on Surface Modification, Structure Interface and Bonding Mechanism of Plant Cellulose Fiber Reinforced Polymer Based Composites". Composite Interfaces, 25(5-7), pp.629-667. https://doi.org/10.1080/09276440.2018.1444832

4. Ighalo, J.O., C.A. Adeyanju, S. Ogunniyi, A.G. Adeniyi and S.A. Abdulkareem, 2020. "An Empirical Review of the Recent Advances in Treatment of Natural Fibers for Reinforced Plastic
Composites". Composite Interfaces, pp.1-36. http://dx.doi.org/10.1080/09276440.2020.1826274

5. Osman, A.F. and M. Mariatti, 2006. "Properties of Aluminum Filled Polypropylene Composites". Polymers \& Polymer Composites, 14(6), pp.623-633. http://dx.doi.org/10.1177/09673911060140060

6. Bhattacharya, S.K., 1996. Metal Filled Polymers, (Properties and Applications). Markel Dekker, Inc.

7. Yin, R., J. Sun, Y. Xiang and C. Shang, 2018. "Recycling and Reuse of Rusted Iron Particles Containing Core-Shell Fe-Feooh for Ibuprofen Removal: Adsorption and Persulfate-Based Advanced Oxidation". Journal of Cleaner Production, 178, pp.441-448. https://doi.org/10.1016/j.jclepro.2018.01.005

8. Ighalo, J.O. and A.G. Adeniyi, 2020. Utilization of Recycled Polystyrene and Aluminum Wastes in the Development of Conductive Plastic Composites: Evaluation of Electrical Properties, in Handbook of Environmental Materials Management C.M. Hussain, Editor., Springer Nature. pp. 1-9. http://dx.doi.org/10.1007/978-3-319-58538-3_228-1

9. Onitiri, M. and E. Akinlabi, 2017. "Effects of Particle Size and Particle Loading on the Tensile Properties of Iron-Ore-TailingFilled Epoxy and Polypropylene Composites". Mechanics of Composite Materials, 52(6), pp.817-828. http://dx.doi.org/10.1007/s11029-017-9633-4

10. Adedayo, S.M. and M.A. Onitiri, 2012. "Tensile Properties of Iron Ore Tailings Filled Epoxy Composites". The West Indian Joumal of Engineering, 35(1), pp.51-59.

11. Sridhar, M. and T. Hammed, 2014. "Turning Waste to Wealth in Nigeria: An Overview”. Journal of Human Ecology, 46(2), pp.195203. https://doi.org/10.1080/09709274.2014.11906720

12. Ng, W.P.Q., H.L. Lam, F.Y. Ng, M. Kamal and J.H.E. Lim, 2012. "Waste-to-Wealth: Green Potential from Palm Biomass in Malaysia". Journal of Cleaner Production, 34, pp.57-65. https://doi.org/10.1016/j.jclepro.2012.04.004

13. Adeniyi, A.G., J.O. Ighalo and C.A. Adeyanju, 2021. "Materialsto-Product Potentials for Sustainable Development in Nigeria". International Journal of Sustainable Engineering, pp.1-8. http://dx.doi.org/10.1080/19397038.2021.1896591

14. Adeyanju, C.A., S. Ogunniyi, J.O. Ighalo, A.G. Adeniyi and S.A. Abdulkareem, 2021. "A Review on Luffa Fibres and Their Polymer Composites”. Journal of Material Science, 56(4), pp.2797-2813. http://dx.doi.org/10.1007/s10853-020-05432-6

15. Adeniyi, A.G., S.A. Adeoye and J.O. Ighalo, 2020. "Sansevieria Trifasciata Fiber and Composites: A Review of Recent Developments". International Polymer Processing, 35(4), pp.344354. http://dx.doi.org/10.3139/217.3914

16. Qureshi, A., A. Mergen, M.S. Eroglu, N.L. Singh and A. Gulluoglu, 2008. "Dielectric Properties of Polymer Composites Filled with Different Metals". Journal of macromolecular Science Pant A, 45(6), pp.462-469. https://doi.org/10.1080/10601320801977756

17. Abdulkareem, S. and A. Adeniyi, 2018. "Preparation and Evaluation of Electrical Properties of Plastic Composites Developed from Recycled Polystyrene and Local Clay". Nigerian Journal of Technological Development, 15(3), pp.98-101. http://dx.doi.org/10.4314/njtd.v15i3.4

18. Dash, C., A. Das and D. Kumar Bisoyi, 2020. "Influence of Pretreatment on Mechanical and Dielectric Properties of Short Sunn Hemp Fiber-Reinforced Polymer Composite in Correlation with Fine Structure of the Fiber". Journal of Composite Materials, pp.1-15. https://doi.org/10.1177/0021998320914071

19. Mohana Krishnudu, D., D. Sreeramulu, P.V. Reddy and P. Rajendra Prasad, 2020. "Influence of Filler on Mechanical and Di-Electric Properties of Coir and Luffa Cylindrica Fiber Reinforced Epoxy Hybrid Composites". Journal of Natural Fibers, pp.1-10. https://doi.org/10.1080/15440478.2020.1745115 
20. Wu, X., Y. Liao, G. Meng, L. T ang, Z. Zhou, Q. Li and W. Huang 2019. "Sio 2/Carbon Fiber-Reinforced PolypropyleneThermoplastic Polyurethane Composites: Electrical Conductivity and Mechanical and Thermal Properties". Iranian Polymer Joumal, 28(6), pp.527-537. https://doi.org/10.1007/s13726-019-00720-8

21. Kulkarni, H.B., P.B. Tambe and G.M. Joshi, 2020. "Influence of Surfactant Assisted Exfoliation of Hexagonal Boron Nitride Nanosheets on Mechanical, Thermal and Dielectric Properties of Epoxy Nanocomposites". Composite Interfaces, 27(6), pp.529-550. https://doi.org/10.1080/09276440.2019.1663115

22. Lee, D., S. Lee, S. Byun, K.-W. Paik and S.H. Song, 2018. "Novel Dielectric Bn/Epoxy Nanocomposites with Enhanced Heat Dissipation Performance for Electronic Packaging". Composites Part A: Applied Science and Manufacturing, 107, pp.217-223. https://doi.org/10.1016/j.compositesa.2018.01.009

23. Adeniyi, A.G. and J.O. Ighalo, 2021. "A Systematic Review of Pure Metals Reinforced Plastic Composites". Iranian Polymer Joumal, pp.1-18. http://dx.doi.org/10.1007/s13726-021-00922-z

24. Ighalo, J.O., C.A. Igwegbe, A.G. Adeniyi and S.A. Abdulkareem, 2021. "Artificial Neural Network Modeling of the Water Absorption Behavior of Plantain Peel and Bamboo Fibers Reinforced Polystyrene Composites". Journal of Macromolecular Science: Part B, pp.1-14 http://dx.doi.org/10.1080/00222348.2020.1866282

25. Ighalo, J.O., A.G. Adeniyi, O.O. Owolabi and S.A. Abdulkareem, 2021. "Moisture Absorption, Thermal and Microstructural Properties of Polymer Composites Developed from Rice Husk and Polystyrene Wastes. ". International Journal of Sustainable Engineering, http://dx.doi.org/10.1080/19397038.2021.1892234

pp.1-9.

6. Adeniyi, A.G., S.A. Abdulkareem, J.O. Ighalo, D.V. Onifade, S.A. Adeoye and A.E. Sampson, 2020. "Morphological and Thermal Properties of Polystyrene Composite Reinforced with Biochar from Elephant Grass (Pennisetum Purpureum)". Journal of Thermoplastic Composite Materials, pp.1-16. http://dx.doi.org/10.1177/0892705720939169
27. Mamza, P.A.P., A. Aliu and R.A. Muhammed, 2010."The Effects of Iron Filings on Some Mechanical and Physical Properties of a Sawdust Particleboard". Nigerian Journal of Basic and Applied Sciences, $18(1)$, pp.112-119. https://doi.org/10.4314/njbas.v18i1.56854

28. Abdulkareem, S.A. and A. Adeniyi, 2017. "Production of Particle Boards Using Polyst yrene and Bamboo Wastes". Nigerian Joumal of Technology, 36(3), pp.788-793. http://dx.doi.org/10.4314/njt.v36i3.18

29. Odetoye, T., A. Adeniyi and O. Akande, 2020. "Valorization of Post-Consumer Polythene Water Sachet and Parinari Polyandra Shell Residue for Composites Production". SN Applied Sciences, 2(11), pp.1-10. https://doi.org/10.1007/s42452-020-03641-x

30. Ighalo, J.O., A.G. Adeniyi and S.A. Abdulkareem, 2021. "Thermal, Functional Group and Microstructural Analysis of Fibrillated Composites Developed from Polystyrene and Plantain Stalk Wastes". Materials Performance and Charactersiation, 10(1), pp.341-352. http://dx.doi.org/10.1520/MPC20200047

31. Abdulkareem, S. and A. Adeniyi, 2019. "Recycling Copper and Polystyrene from Solid Waste Stream in Developing Conductive Composites". The Journal of Solid Waste Technology and Management, $45(1), \quad$ pp.39-44. https://doi.org/10.5276/JSWTM.2019.39

32. Gelinas, C., F. Chagnon and S. Pelletier, Development of an IronResin Composite Material for Soft Magnetic Applications. 1999, Quebec Metal Powder: Canada. pp. 85-97.

33. Sudheer, M., 2016. "Study of Wear Behaviour of Recycled Metal Powder Filled Epoxy Composites Using Factorial Analysis". American Journal of Materials Science, 6(4A), pp.82-87. https://doi.org/10.5923/c.materials.201601.16

34. Adeniyi, A.G., J.O. Ighalo, S.A. Abdulkareem and R. Akinwolemiwa, 2021. "Water Absorption, Thermal and Microstructural Properties of Plastic Composites Developed from Isoberlinia Doka Wood Sawdust and Polystyrene Wastes". Joumal of The Institution of Engineers (India): Series E, pp.1-10. http://dx.doi.org/10.1007/s40034-020-00203-z

\section{COPYRIGHTS}

(C2021 The author(s). This is an open access article distributed under the terms of the Creative Commons Attribution (CC BY 4.0), which permits unrestricted use, distribution, and reproduction in any medium, as long as the original authors and source are cited. No permission is required from the authors or the publishers.

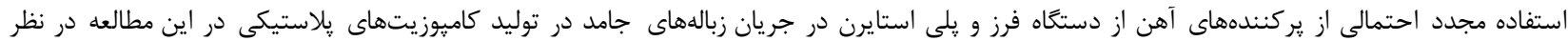

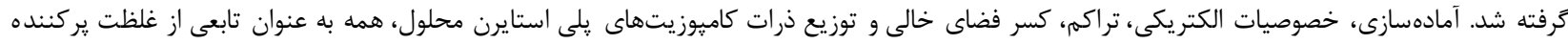

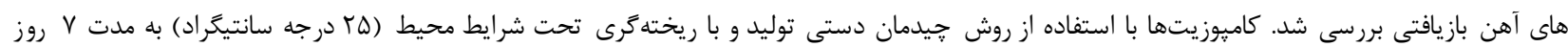

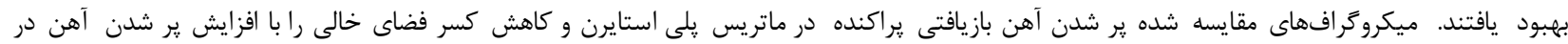

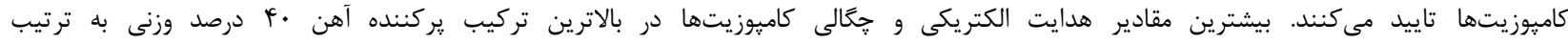

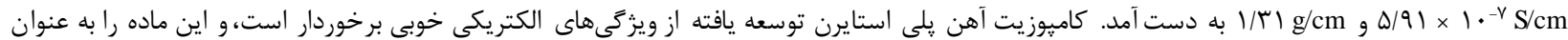

$$
\text { ماده جايكزين براى فلزات مناسب مىنمايد. }
$$

